\title{
Ekstraksi Kalium dari Abu Tandan Kosong Sawit sebagai Katalis pada Reaksi Transesterifikasi Minyak Sawit
}

\author{
Mohammad Imaduddin ${ }^{1}$, Yoeswono², Karna Wijaya ${ }^{1}$, dan Iqmal Tahir ${ }^{*}$ \\ 1) Physical Chemistry Laboratory, Chemistry Department, Faculty of Mathematics and \\ Natural Sciences, Universitas Gadjah Mada, Sekip Utara Yogyakarta, Indonesia 55281 \\ 2) Training Center BP Migas, Jl. Sorogo no 1, Cepu, Central Java, Indonesia
}

Received: 25 September 2008; Accepted: 5 October 2008

\begin{abstract}
Process of the transesterification reaction of palm oil with methanol by using ash of palm empty fruit bunches (EFB) as base catalyst has been conducted. The studied variables were effect of weight ash of EFB $(5,10,15,20,25 \mathrm{~g})$ and the molar ratio $(3: 1 ; 6: 1 ; 9: 1$; and $12: 1)$ of methanol to palm oil. Sample of ash was prepared through heating, screening, and reashing. A certain amount of ash was extracted in methanol with mixing for about $1 \mathrm{~h}$ at room temperature and the product was used as catlayst for transesterification process. The composition of the methyl esters (biodiesel) was analyzed using GC-MS and 1H NMR, whereas characters of biodiesel were analyzed using ASTM methods. The results of AAS analysis showed that potassium carbonate content in ash of EFB was $25.92 \% \mathrm{w} / \mathrm{w}$. The main components of biodiesel were mixture of methyl palmitate and methyl oleat as the major compounds. The increasing of EFB ash weight (catalyst concentration) in reaction of transesterification enhanced the biodiesel conversion of $53.0 ; 76.9 ; 88.2 ; 90.5$ and $97.8 \%(\mathrm{w} / \mathrm{w})$ respectively. The increasing of the molar ratio of methanol to palm oil, the biodiesel conversion enhanced too, that were $74.0 ; 90.5 ; 92.3$ and $98.8 \%(\mathrm{w} / \mathrm{w})$ respectively. The properties of biodiesel were relatively conformed with specification of biodiesel (ASTM D 6751). C 2008 CREC UNDIP. All rights reserved.
\end{abstract}

Keywords: biodiesel conversion, transesterification, palm oil, palm empty fruit bunch

\section{Pendahuluan}

Akibat ketergantungan manusia terhadap minyak bumi tak terbarukan dewasa ini yang semakin meningkat, menjadikan minyak bumi sebagai kebutuhan primer. Diperkirakan beberapa tahun ke depan cadangan minyak bumi akan habis sehingga membuat para peneliti berlomba untuk membuat bahan bakar alternatif pengganti minyak bumi. Selain karena berkurangnya cadangan minyak bumi, hal lain yang mendorong penelitian tersebut dilakukan adalah peristiwa pemanasan global akibat emisi gas-gas rumah kaca yang salah satunya berasal dari pembakaran minyak bumi.

Biodiesel merupakan bahan bakar yang ramah lingkungan dan dapat diperbaharui serta bersifat

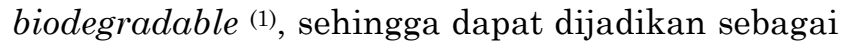
sumber energi alternatif pilihan. Konsep bahan bakar bersih antara lain meliputi: pengurangan kadar belerang, penambahan senyawa-senyawa oksigenat, pengurangan senyawa aromatik, dan peningkatan angka cetan

* Corresponding Author. Telp/Fax : (0274)545188;

E-mail address: iqmal@ugm.ac.id 
atau oktana (2).

Biodiesel pada umumnya disintesis melalui transesterifikasi dengan alkohol ringan menggunakan katalis basa konvensional. Literatur mengenai penggunaan katalis konvensional seperti $\mathrm{NaOH}, \mathrm{KOH}, \mathrm{K}_{2} \mathrm{CO}_{3}$, dan lain-lain sebagai katalis basa telah banyak dipublikasikan. Tetapi masih sedikit literatur yang mengkaji pemanfaatan abu tandan kosong sawit (abu TKS) sebagai pengganti katalis konvensional. Selama ini, TKS yang merupakan hasil produk samping pengolahan sawit hanya digunakan sebagai bahan bakar boiler dan abu hasil pembakaran tersebut dimanfaatkan sebagai pengganti pupuk (3). Abu hasil pembakaran TKS mempunyai kadar kalium yang tinggi (45-50 \%) (4). Bila abu ini dilarutkan dalam air akan diperoleh larutan alkalis ${ }^{(5)}$.

Beberapa literatur telah melaporkan kajian mengenai pemanfaatan abu TKS sebagai katalis basa dalam sintesis biodiesel. Peneliti sebelumnya melaporkan kajian pemanfaatan abu TKS sebagai sumber katalis $\mathrm{K}_{2} \mathrm{CO}_{3}$ untuk sintesis biodiesel dari minyak kelapa (6). Peneliti lainnya melaporkan pula kajian pengaruh abu TKS terhadap transesterifikasi minyak sawit menjadi biodiesel (7). Berdasarkan kedua laporan tersebut dijelaskan bahwa preparasi abu dilakukan dengan cara dipanaskan dalam oven pada temperatur $110{ }^{\circ} \mathrm{C}$. Untuk proses ekstraksi katalis dilakukan melalui perendaman abu TKS dalam media metanol dan didiamkan (tanpa mendapat perlakuan) selama 48 jam pada temperatur kamar.

Dalam penelitian ini penulis mengkaji transesterifikasi minyak sawit dengan metanol menggunakan katalis abu TKS. Untuk lebih dapat meningkatkan efisiensi pemanfaatan kalium dalam abu TKS, maka perlu dilakukan proses reashing dan ekstraksi yang disertai pengadukan. Hal ini dilakukan untuk mengoptimumkan jumlah katalis yang dapat terekstraksi dan mempersingkat waktu ekstraksi sehingga diharapkan pembuatan biodiesel (metil ester) menjadi lebih efisien. Pengembangan bahan bakar biodiesel sendiri dapat pula mengurangi ketergantungan masyarakat pada bahan bakar fosil.

\section{Bahan dan Metode Penelitian}

\section{Preparasi abu tandan kosong sawit}

Abu TKS (dari pabrik minyak sawit-Jambi) dipanaskan menggunakan oven pada temperatur $110{ }^{\circ} \mathrm{C}$ selama 2 jam untuk menghilangkan air kemudian disaring dengan ayakan 100 mesh.
Selanjutnya abu diabukan kembali (reashing) sampai temperatur $700{ }^{\circ} \mathrm{C}$ untuk menghilangkan sisa-sisa karbon. Penentuan kadar kalium dalam abu TKS dilakukan dengan spektrometer serapan atom (AAS, Varian FS 220) serta untuk mengetahui keberadaan ion karbonat dilakukan uji alkalinitas.

\section{Transesterifikasi minyak sawit}

Sejumlah tertentu abu TKS diaduk dalam 75 $\mathrm{mL}$ metanol teknis (Brataco Chemika) $(\mathrm{BM}=$ 32,04) selama 1 jam pada temperatur kamar. Setelah disaring, ekstrak yang diperoleh dicukupkan volumenya sehingga diperoleh rasio molar metanol/minyak tertentu yang akan digunakan untuk melakukan reaksi transesterifikasi terhadap $250 \mathrm{~g}$ minyak sawit (dari pasar tradisional di Jogjakarta).

Reaksi transesterifikasi dilakukan selama 2 jam. Setelah reaksi berjalan 2 jam, pengadukan dihentikan, campuran yang terbentuk dituang dalam corong pisah, dibiarkan terjadi pemisahan selama 2 jam pada temperatur kamar. Lapisan metil ester yang terbentuk dipisahkan dari lapisan gliserol, selanjutnya didistilasi sampai temperatur $74{ }^{\circ} \mathrm{C}$ untuk menghilangkan sisa metanol. Penghilangan sisa katalis dan gliserol dalam metil ester dilakukan dengan pencucian menggunakan air berulang kali, sampai diperoleh lapisan air yang jernih. Kemudian metil ester dikeringkan dengan penambahan $\mathrm{Na}_{2} \mathrm{SO}_{4}$ anhidrat p.a. (Merck).

Prosedur proses transesterifikasi tersebut dilakukan dengan variasi berat abu untuk 5, 10, 15, 20 dan 25 g (rasio molar metanol/minyak 6:1, waktu reaksi 2 jam, temperatur kamar, dan kecepatan pengadukan dijaga konstan), dan variasi rasio molar metanol/minyak untuk $3: 1$, 6:1, 9:1 dan 12:1 (berat abu terpilih, waktu reaksi 2 jam, temperatur kamar, dan kecepatan pengadukan dijaga konstan).

\section{Analisis hasil Transesterifikasi}

Komposisi metil ester minyak sawit dianalisis menggunakan kromatografi gas-spektrometer massa (GC-MS, Shimadzu QP-2010S). Berat molekul minyak sawit ditentukan berdasarkan nilai rerata dari seluruh berat molekul komponen minyak sawit dalam bentuk trigliseridanya. Berat molekul masing-masing trigliserida adalah tiga kali berat molekul metil esternya dikurangi 4,032 yang merupakan selisih jumlah proton antara trigliserida dan metil esternya.

Untuk mengetahui persentase konversi metil ester yang diperoleh digunakan spektrometer resonansi magnetik kulit proton $\left({ }^{1} \mathrm{H}\right.$ NMR, JEOLMY60) (60 MHz, solvent $\left.\mathrm{CDCl}_{3}\right)$. Dengan ${ }^{1} \mathrm{H}-$ 
NMR, puncak proton-proton metoksi dari metil ester tampak pada $\delta= \pm 3,7$ ppm, puncak protonproton $\alpha$-metilen pada $\delta= \pm 2,3$ ppm yang terdapat dalam semua senyawa asam lemak, dan puncak proton-proton gliseril pada trigliserida pada $\delta= \pm$ 4,2 $\mathrm{ppm}^{(8)}$.

Konversi metil ester (\%) ditentukan dengan persamaan 1 .

$$
\mathrm{C}_{\mathrm{ME}},(\%)=100 \mathrm{X} \frac{5 \mathrm{I}_{\mathrm{ME}}}{5 \mathrm{I}_{\mathrm{ME}}+9 \mathrm{I}_{\mathrm{TG}}}
$$

Keterangan:

$\mathrm{C}_{\mathrm{ME}}=$ konversi metil ester, (\%)

$\mathrm{I}_{\mathrm{ME}}=$ nilai integrasi puncak metoksi pada metil ester, (\%), dan

$\mathrm{I}_{\mathrm{TG}}=$ nilai integrasi puncak gliserol pada trigliserida, (\%).

Trigliserida yang tidak terkonversi ditentukan dengan persamaan 2 .

$$
\mathrm{C}_{\mathrm{TG}},(\%)=100-\mathrm{C}_{\mathrm{ME}}
$$

Keterangan:

$\mathrm{C}_{\mathrm{TG}}=$ trigliserida yang tidak terkonversi, (\%), dan $\mathrm{C}_{\mathrm{ME}}=$ konversi metil ester, (\%).

Sisa trigliserida $(\% \mathrm{~b} / \mathrm{b})$ dapat ditentukan dengan persamaan 3 .

$$
\mathrm{TG}=\frac{\mathrm{C}_{\mathrm{TG}} \times \mathrm{xM}_{\mathrm{G}} \times \mathrm{d}_{\mathrm{TG}}}{\left(\mathrm{C}_{\mathrm{TG}} \times \mathrm{BM}_{\mathrm{G}} \times \mathrm{d}_{\mathrm{TG}}\right)+\left(\mathrm{C}_{\mathrm{ME}} \times \mathrm{MM}_{\mathrm{ME}} \times \mathrm{d}_{\mathrm{ME}}\right)}
$$

Keterangan:

$\mathrm{BM}_{\mathrm{TG}}=$ berat molekul trigliserida, g. mol-1,

$\mathrm{BM}_{\mathrm{ME}}=$ berat molekul metil ester, $\mathrm{g} \cdot \mathrm{mol}^{-1}$,

$\mathrm{d}_{\mathrm{TG}}=$ berat jenis trigliserida, $\mathrm{kg} \cdot \mathrm{m}^{-3}$, dan

$\mathrm{d}_{\mathrm{ME}}=$ berat jenis metil ester, $\mathrm{kg} \cdot \mathrm{m}^{-3}$.

Faktor 5 dan 9 pada persamaan 1 adalah menunjukkan jumlah proton yang terdapat pada gliserol dalam molekul trigliserida mempunyai 5 proton dan tiga gugus metoksi pada tiga molekul metil ester yang dihasilkan dari satu molekul trigliserida mempunyai 9 proton ${ }^{(8)}$.

Kualitas biodiesel selanjutnya diuji dengan beberapa metode uji standar ASTM untuk menetapkan kesesuaian biodiesel yang dihasilkan dengan spesifikasi biodiesel ASTM D 6751.

\section{Hasil dan Pembahasan}

\section{Analisis Bahan Baku Minyak Sawit}

Sebelum minyak sawit digunakan sebagai bahan baku pembuatan biodiesel, terlebih dahulu minyak sawit dianalisis dengan menggunakan GCMS untuk mengetahui komposisi asam-asam lemak yang terkandung didalamnya dan untuk menghitung berat molekul minyak sawit (dalam bentuk trigliserida). Sampel yang akan dianalisisis menggunakan GC harus memiliki titik didih yang rendah atau mudah menguap. Oleh karena itu, minyak sawit yang memiliki titik didih relatif

\begin{tabular}{|c|c|c|c|}
\hline \multirow{3}{*}{ Nama trivial (sistematik); akronim } & \multicolumn{3}{|c|}{ Kadar asam lemak, (\%) } \\
\hline & \multicolumn{2}{|c|}{ Minyak sawit } & \multirow{2}{*}{$\frac{\text { Minyak biji sawit }}{\text { Kurata et al. }{ }^{(10)}}$} \\
\hline & Bahan baku & $\begin{array}{c}\text { Darnoko dan } \\
\text { Cheryan (9) }\end{array}$ & \\
\hline Asam kaprat (asam dekanoat); C10:0 & - & - & 11,7 \\
\hline Asam laurat (asam dodekanoat); C12:0 & 0,08 & 0,35 & 69,3 \\
\hline Asam miristat (asam tetradekanoat); C14:0 & 1,23 & 1,08 & 9,7 \\
\hline Asam palmitat (asam heksadekanoat); C16:0 & 39,79 & 43,79 & 2,3 \\
\hline Asam palmitoleat (asam heksadekenoat); C16:1 & 0,17 & 0,15 & - \\
\hline Asam margarat (asam heptadekanoat); C17:0 & 0,11 & - & - \\
\hline Asam stearat (asam oktadekanoat); C18:0 & 5,75 & 4,42 & 0,3 \\
\hline Asam oleat (asam oktadekenoat); C18:1 & 52,21 & 39,90 & 2,2 \\
\hline Asam linoleat (asam oktadekadienoat); C18:2 & - & 9,59 & 0,4 \\
\hline Asam linolenat (asam oktadekatrienoat); C18:3 & - & 0,17 & - \\
\hline Asam arakidat (asam eikosanoat); C20:0 & 0,44 & 0,38 & - \\
\hline Asam gadoleat (asam eikosenoat); C20:1 & 0,17 & - & - \\
\hline Asam-asam lainnya & 0,05 & tidak ada data & 4,1 \\
\hline Total & 100,00 & 99,83 & 100,0 \\
\hline
\end{tabular}
tinggi harus dibuat senyawa turunannya (senyawa

Tabel 1. Komposisi asam lemak minyak sawit yang digunakan sebagai bahan baku 
ester) terlebih dahulu supaya memiliki titik didih relatif rendah sehingga mudah menguap.

Berdasarkan hasil analisis GC-MS, komponen asam lemak yang dominan dalam sampel minyak sawit yang digunakan pada penelitian ini adalah asam palmitat dan asam oleat. Komposisi minyak sawit dalam bentuk asam lemaknya disajikan dalam Tabel 1.

Berdasarkan data komposisi metil ester minyak sawit maka dapat ditentukan bahwa berat molekul minyak sawit (dalam bentuk trigliseridanya) adalah $852,97 \mathrm{~g} \cdot \mathrm{mol}^{-1}$, sedangkan berat molekul metil esternya adalah 857,002 g. $\mathrm{mol}^{-1}$.

\section{Analisis Kadar dan Tingkat Pelepasan Kalium dari Sampel Abu TKS}

Berdasarkan hasil analisis AAS diperoleh bahwa kandungan kalium pada abu TKS yang digunakan dalam penelitian ini adalah sebesar $25,92 \%(\mathrm{~b} / \mathrm{b})$.

Uji alkalinitas dilakukan dengan metode titrasi asidimetri yang bertujuan untuk mengetahui bentuk senyawa kalium yang terdapat dalam abu TKS. Kalium yang terdapat pada abu TKS dalam bentuk senyawa karbonat (6). Selama pembakaran TKS dalam boiler berada pada temperatur di bawah $900{ }^{\circ} \mathrm{C}$, senyawa yang terdapat dalam abu TKS dimungkinkan dalam bentuk senyawa karbonat (7). Pada Tabel 2, dalam abu TKS terdapat anion-anion karbonat dan bikarbonat yang mana konsentrasi ion karbonat adalah yang paling besar sehingga dapat disimpulkan bahwa kalium yang terdapat dalam abu TKS adalah dalam bentuk senyawa kalium karbonat $\left(\mathrm{K}_{2} \mathrm{CO}_{3}\right)$.

Preparasi abu dapat mempengaruhi konsentrasi ion karbonat yang terkandung didalamnya. Hal ini dapat dilihat dari hasil penelitian yang dilakukan oleh peneliti sebelumnya yang melakukan preparasi terhadap abu TKS dengan cara hanya dipanaskan dalam oven pada temperatur $110{ }^{\circ} \mathrm{C}(6,7)$. Dari hasil uji alkalinitas diperoleh bahwa konsentrasi ion karbonat di dalam abu sebesar 196,627 g/kg. Bila dibandingkan dengan hasil penelitian ini (abu

Tabel 2. Konsentrasi anion yang terdapat dalam abu TKS hasil uji alkalinitas

\begin{tabular}{|c|c|}
\hline Alkalinitas & Konsentrasi dalam abu $(\mathrm{g} / \mathrm{kg})$ \\
\hline $\mathrm{HCO}_{3}$ - (bikarbonat) & 43,75 \\
$\mathrm{CO}_{3}=$ (karbonat) & 375,86 \\
\hline
\end{tabular}

TKS dipanaskan dalam oven dan direashing dalam furnace), konsentrasi ion karbonat hampir dua kali lebih besar dibandingkan konsentrasi ion karbonat dari abu TKS yang hanya dipanaskan dalam oven saja.

Dalam penelitian ini abu TKS telah diaduk dengan persentase berat terhadap minyak berturut-turut $2,4,6,8$ dan $10 \%(\mathrm{~b} / \mathrm{b})$ dalam 75 $\mathrm{mL}$ metanol teknis selama 1 jam pada temperatur kamar. Ekstrak hasil pengadukkan dianalisis kadar kaliumnya dengan AAS dan diperoleh hasil seperti dalam Tabel 3. Tampak bahwa jumlah kalium yang terekstraksi meningkat dengan peningkatan persentase berat abu yang diaduk pada kondisi tersebut.

\section{Pengaruh Persentase Berat Abu TKS Terhadap Minyak Pada Produk Biodiesel}

Seperti yang telah diuraikan di atas bahwa senyawa yang terdapat dalam abu TKS adalah berupa kalium karbonat. Oleh karena itu, dalam penelitian ini dilakukan pembuatan biodiesel dalam media metanol dengan menggunakan kalium karbonat konvensional guna memastikan bahwa senyawa tersebut dapat digunakan sebagai katalis basa dalam pembuatan biodiesel. Kondisi reaksi transesterifikasi dilakukan selama 2 jam pada temperatur kamar dengan persentase berat katalis $1 \%(\mathrm{~b} / \mathrm{b})$ terhadap berat minyak dan rasio molar metanol/minyak 6:1. Hasil transesterifikasi kemudian dianalisis menggunakan ${ }^{1} \mathrm{H}$ NMR untuk mengetahui persentase konversi biodiesel. Hasil analisis menunjukkan bahwa tingkat konversi metil ester (biodiesel) yang diperoleh adalah sebesar 95,3\% (menggunakan persamaan 1). Dengan demikian dapat dinyatakan bahwa $\mathrm{K}_{2} \mathrm{CO}_{3}$ dapat digunakan sebagai katalis basa dalam reaksi transesterifikasi.

Berdasarkan pada Tabel 4, tampak bahwa semakin besar persentase berat abu terhadap minyak, maka persentase konversi biodiesel yang dihasilkan juga semakin besar. Semakin besarnya persentase berat abu ini berarti persentase berat K2CO3 juga semakin besar. Katalis disini dapat mempercepat reaksi dengan cara menurunkan energi aktivasi sehingga laju pembentukan metil ester menjadi lebih cepat. Pada persentase berat abu $10 \%(\mathrm{~b} / \mathrm{b})$ akan menghasilkan spesies ion metoksida lebih banyak sehingga tumbukan terhadap molekul-molekul trigliserida semakin meningkat dan persentase konversi biodiesel semakin besar.

Konsentrasi katalis yang semakin besar tidak menyebabkan bergesernya reaksi ke kanan (ke arah pembentukan metil ester), namun menyebabkan kualitas pertemuan antar reaktan semakin meningkat yang dapat menurunkan 
Tabel 3 Kadar kalium dalam ekstrak abu TKS dengan metanol teknis

\begin{tabular}{|c|c|c|}
\hline Berat abu, g & Kalium terekstraksi, $\mathrm{g}$ & $\begin{array}{r}\text { Kalium terekstraksi } \\
\text { sebagai } \mathrm{K}_{2} \mathrm{CO}_{3}, \mathrm{~g}\end{array}$ \\
\hline 5,0328 & 0,1871 & 0,6620 \\
\hline 10,0241 & 0,2541 & 0,8991 \\
\hline 15,0413 & 0,3723 & 1,3174 \\
\hline 20,0265 & 0,4572 & 1,6178 \\
\hline 25,0176 & 0,4960 & 1,7551 \\
\hline
\end{tabular}

Tabel 4. Persentase konversi biodiesel hasil transesterifikasi pada variasi persentase berat abu terhadap minyak sawit

\begin{tabular}{|l|c|c|c|}
\hline Kode & $\begin{array}{l}\text { B e r a t } \\
\text { abu TKS, } \\
\mathrm{g}\end{array}$ & $\begin{array}{l}\text { Berat } \mathrm{K}_{2} \mathrm{CO}_{3} \text { dalam TKS } \\
\text { terhadap minyak, \% b/b }\end{array}$ & $\begin{array}{l}\text { Konversi, } \\
\%\end{array}$ \\
\hline $\begin{array}{l}\mathrm{TK} / 6: \\
1\end{array}$ & - & - & 0,00 \\
\hline $2 / 6: 1$ & 5,0161 & 0,2648 & 53,0 \\
\hline $4 / 6: 1$ & 10,0028 & 0,3596 & 76,9 \\
\hline $6 / 6: 1$ & 15,0344 & 0,5270 & 88,2 \\
\hline $8 / 6: 1$ & 20,0186 & 0,6471 & 90,5 \\
\hline $\begin{array}{l}10 / 6: \\
1\end{array}$ & 25,0227 & 0,7020 & 97,8 \\
\hline
\end{tabular}

Tabel 5. Pengaruh persentase berat abu TKS terhadap minyak pada beberapa sifat fisik biodiesel

\begin{tabular}{|l|c|c|c|c|c|c|c|c|}
\hline \multicolumn{1}{|c|}{ Sifat } & Metode ASTM & MG & TK/6:1 & $2 / 6: 1$ & $4 / 6: 1$ & $6 / 6: 1$ & $8 / 6: 1$ & $10 / 6: 1$ \\
\hline Viskositas kinematik, $40^{\circ} \mathrm{C}, \mathrm{mm}^{2} \mathrm{~s}^{-1}$ & D 445 & 40,7 & 39,9 & 16,7 & 7,7 & 7,4 & 5,9 & 5,7 \\
\hline Densitas, $\mathrm{kg} \mathrm{m}^{-3}$ & D 1298 & 914,9 & 912,2 & 898,5 & 884,6 & 882,6 & 879,9 & 878,0 \\
\hline Titik nyala $\left({\text { closed cup }),{ }^{\circ} \mathrm{C}}^{\circ}\right.$ & D 93 & 270 & 208 & 140 & 176 & 176 & 141 & 136 \\
\hline Titik kabut, ${ }^{\circ} \mathrm{C}$ & D 2500 & 26 & 26 & 20 & 17 & 17 & 16 & 15 \\
\hline Titik tuang, ${ }^{\circ} \mathrm{C}$ & D 97 & 21 & 21 & 17 & 15 & 14 & 14 & 12 \\
\hline Gliserol total, $\%$ (b/b) & $*$ & 100,0 & 100,0 & 47,4 & 23,6 & 12,1 & 9,8 & 2,3 \\
\hline
\end{tabular}

energi pengaktifan. Tampak pada Tabel 4 bahwa reaksi transesterifikasi tanpa menggunakan katalis tidak dihasilkan biodiesel (persentase konversi nol \%). Meskipun tanpa katalis, dimungkinkan reaksi tetap terjadi namun lajunya sangat lambat akibat energi aktivasi yang terlalu tinggi dan produk yang dihasilkan pun sangat sedikit sehingga tidak dapat terdeteksi oleh alat.

Pada Tabel 5 disajikan hasil analisis karakter fisik dengan metode standar ASTM terhadap produk-produk biodiesel hasil transesterifikasi minyak sawit dalam media metanol pada rasio molar metanol/minyak berat abu TKS terhadap minyak. Data menunjukkan 6:1 dengan melakukan variasi persentase bahwa pada persentase berat abu 8 dan $10 \%$ (b/b) terhadap minyak sawit telah dihasilkan viskositas yang sesuai dan begitu pula sifat fisik lainnya juga telah memenuhi standar ASTM D 6751.

Selain metanol, viskositas dipengaruhi juga oleh panjang rantai (jumlah atom C) dan derajat kejenuhan dari komponen penyusun bahan baku biodiesel. Semakin meningkat panjang rantai dan derajat kejenuhan maka viskositas akan semakin besar. Viskositas akan semakin rendah dengan adanya ikatan rangkap dalam komponen penyusun bahan baku biodiesel. Namun konfigurasi ikatan rangkap trans akan memberikan viskositas yang lebih besar dari konfigurasi ikatan rangkap cis, sedangkan letak ikatan rangkap hanya sedikit berpengaruh terhadap viskositas. Keberadaan rantai cabang juga tidak atau sedikit berpengaruh terhadap viskositas (11).

Mono- ataupun digliserida mempunyai viskositas yang mirip dengan viskositas biodiesel, sehingga keberadaan monogliserida dan digliserida sebagai hasil dari reaksi yang kurang sempurna tidak mempengaruhi viskositas (12). Berbeda halnya dengan trigliserida yang mempunyai viskositas yang lebih tinggi dari metil ester (biodiesel), tidak sempurnanya reaksi dimana trigliserida yang tidak terkonversi menjadi metil ester menyebabkan viskositas produk yang dihasilkan masih relatif tinggi dan persentase konversinya pun menjadi rendah.

\section{Pengaruh Rasio Molar Metanol/Minyak terhadap Produk Biodiesel}

Berdasarkan data pada Tabel 6, tampak bahwa persentase konversi biodiesel meningkat seiring dengan semakin besar rasio molar metanol/ minyak. Dengan menggunakan metanol berlebih maka reaksi dapat digeser ke kanan (ke arah 
Tabel 6. Persentase konversi biodiesel hasil transesterifikasi minyak sawit pada variasi rasio molar metanol/minyak

\begin{tabular}{|l|c|c|}
\hline \multicolumn{1}{|c|}{ Kode } & Rasio molar metanol/minyak & Konversi, $\%$ \\
\hline $8 / 3: 1$ & $3: 1$ & 74,0 \\
\hline $8 / 6: 1$ & $6: 1$ & 90,5 \\
\hline $8 / 9: 1$ & $9: 1$ & 92,3 \\
\hline $8 / 12: 1$ & $12: 1$ & 98,8 \\
\hline
\end{tabular}

Tabel 7. Pengaruh rasio molar metanol/minyak terhadap beberapa sifat fisik biodiesel

\begin{tabular}{lcrrrr}
\hline \multicolumn{1}{c}{ Sifat } & Metode ASTM & $8 / 3: 1$ & $8 / 6: 1$ & $8 / 9: 1$ & $8 / 12: 1$ \\
\hline Viskositas kinematik, $40{ }^{\circ} \mathrm{C}, \mathrm{mm}^{2} \cdot \mathrm{s}^{-1}$ & D 445 & 10,3 & 5,9 & 5,5 & 5,1 \\
Densitas, kg. m ${ }^{-3}$ & D 1298 & 890,3 & 879,9 & 877,0 & 875,6 \\
Titik nyala (closed cup), ${ }^{\circ} \mathrm{C}$ & D 93 & 176,0 & 141,0 & 168,0 & 158,0 \\
Titik kabut, ${ }^{\circ} \mathrm{C}$ & D 2500 & 16 & 16 & 14 & 15 \\
Titik tuang, ${ }^{\circ} \mathrm{C}$ & D 97 & 13 & 14 & 11 & 13 \\
Gliserol total, $\%$ (b/b) & $*$ & 26,4 & 9,8 & 7,9 & 1,2 \\
\hline
\end{tabular}

Keterangan:

* = hasil perhitungan berdasarkan persamaan 3

pembentukan produk) untuk menghasilkan konversi yang maksimum. Apabila digunakan rasio molar yang terlalu tinggi akan menyebabkan pemisahan gliserol menjadi sulit karena peningkatan kelarutan. Peningkatan kelarutan gliserol dalam metil ester akan mendorong reaksi berbalik ke kiri dengan membentuk monogliserida (1), sehingga konversi metil ester menjadi berkurang.

Pada Tabel 6 tampak juga bahwa mulai rasio molar metanol/minyak 6:1-12:1 peningkatan konversi biodiesel relatif tidak signifikan. Transesterifikasi dengan katalis basa sebaiknya pada rasio molar alkohol/minyak 6:1, apabila di atas perbandingan tersebut tidak meningkatkan hasil konversi alkil ester secara signifikan (13).

Rasio molar alkohol/minyak juga berpengaruh terhadap distribusi katalis di antara lapisan alkil ester dan gliserol. Rasio molar metanol/minyak $3: 1$, katalis lebih tertarik ke dalam lapisan gliserol, sedangkan dengan penggunaan alkohol berlebih, katalis akan terdistribusi merata dalam lapisan alkil ester dan gliserol (1).

Produk-produk biodiesel yang dihasilkan pada transesterifikasi dengan variasi rasio molar metanol/minyak telah diuji sifat fisiknya dengan metode standar ASTM, seperti yang disajikan dalam Tabel 7. Data menunjukkan bahwa sebagian besar sifat fisik dari biodiesel minyak sawit telah memenuhi standar ASTM D 6751.

\section{Kondisi Optimum Reaksi}

Berdasarkan pada hasil penelitian ini dapat ditentukan bahwa kondisi optimum reaksi dicapai pada persentase berat abu TKS 8\% (b/b) terhadap minyak dengan rasio molar metanol/ minyak 6:1. Pada kondisi tersebut diperoleh tingkat konversi biodiesel sebesar 90,5\%.

Apabila dibandingkan dengan hasil penelitian yang dilakukan oleh peneliti-peneliti sebelumnya yang menggunakan minyak kelapa dan minyak sawit, kondisi optimum reaksi yang dicapai dalam penelitian yang menggunakan minyak kelapa adalah pada persentase berat abu TKS 4\% (b/b) terhadap minyak dengan rasio molar metanol/minyak $12: 1$ dan pada kondisi tersebut diperoleh tingkat konversi biodiesel sebesar $81,5 \%{ }^{(6)}$. Kondisi optimum reaksi dalam penelitian yang menggunakan minyak sawit dicapai pada persentase berat abu TKS 6\% (b/b) terhadap minyak dengan rasio molar metanol/ minyak 9:1 dan pada kondisi tersebut diperoleh tingkat konversi biodiesel sebesar 84,1\% (7). 
Pada hasil penelitian-penelitian tersebut dapat diketahui terdapat perbedaan kondisi optimum reaksi meskipun sama-sama menggunakan abu TKS sebagai katalis basa, hal ini dikarenakan abu TKS yang diperoleh berasal dari tempat yang berbeda sehingga komposisi kimia didalamnya juga berbeda. Selain itu, perbedaan minyak yang digunakan sebagai bahan baku pembuatan biodiesel juga berpengaruh terhadap kondisi optimum reaksi yang dicapai. Minyak sawit dan minyak kelapa memiliki komponen penyusun utama yang berbeda. Untuk penggunaan minyak yang sama belum tentu memiliki komponen penyusun utama yang sama. Hal ini dibuktikan dari hasil analisis komponen penyusun utama minyak sawit yang digunakan oleh peneliti sebelumnya berupa asam palmitat (7), sedangkan pada penelitian ini komponen penyusun utamanya berupa asam palmitat dan asam oleat.

\section{Kesimpulan}

Logam kalium sebagai kalium karbonat merupakan komponen terbesar dalam abu TKS $(25,92 \%(b / b))$ dan dibuktikan bahwa abu TKS ini mempunyai potensi untuk digunakan sebagai sumber katalis basa dalam proses transesterifikasi minyak sawit. Peningkatan jumlah abu TKS yang digunakan dalam reaksi transesterifikasi, akan meningkatkan konversi. biodiesel yang diperoleh. Pada masing-masing persentase berat abu TKS terhadap berat minyak diperoleh persentase konversi biodiesel berturut-turut: $2 \%=53,0 \%, 4 \%$ $=76,9 \%, 6 \%=88,2 \%, 8 \%=90,5 \%$, dan $10 \%=$ $97,8 \%$.

Peningkatan rasio molar metanol/minyak, akan meningkatkan konversi biodiesel. Pada masing-masing variasi mol metanol/minyak diperoleh persentase konversi biodiesel berturutturut: $3: 1=74,0 \%, 6: 1=90,5 \%, 9: 1=92,3 \%$, dan $12: 1=98,8 \%$.

Semakin besar persentase konversi biodiesel yang dihasilkan baik pada variasi persentase berat abu TKS terhadap minyak maupun pada variasi rasio molar metanol/minyak maka sifat fisik biodiesel makin mendekati atau sesuai dengan spesifikasi Biodiesel ASTM D 6751.

\section{Daftar Pustaka}

1. Encinar, J. M., Gonzales J. F., Rodriguez, J. J., dan Tejedor A., 2002, Biodiesel Fuels from Vegetable Oils: Transesterifikasi of Cyanara Cardunculus L. Oils with Ethanol, Energy Fuels, 16, 443-450.

2. Sayles, S., dan Ohmes, R., 2005, Clean Fuels: What are the Issues?, Hydrocarbon Process, 2, $84,39-43$.
3. Saletes, S., Caliman, J. P., dan Raham, D., 2004, Study of Mineral Nutrient Losses from Oil Palm Empty Fruit Bunches During Temporary Strorage, J. Oil Palm Res., 16, 1, 11-21.

4. Kittikun, A. H., Prasertsan, P., Srisuwan, G., dan Krause, A., 2000, Environmental Management for Palm Oil Mill, http:/l www.ias.unu.edu/, 15 Desember 2007.

5. Onyegbado, C. O., Iyagba, E. T., dan Offor, O. J., 2002, Solid Soap Production using Plantain Peel Ash as Source of Alkali, J. Appl. Sci. \& Environ. Manage., 6, 1, 73-77.

6. Yoeswono, Triyono, dan Tahir, I., 2007, The Use of Ash of Palm Empty Fruits Bunches as a Source of $\mathrm{K}_{2} \mathrm{CO}_{3}$ Catalyst for Synthesis of Biodiesel from Coconut Oil with Methanol, Proceeding International Confrence of Chemical Science, Yogyakarta, Indonesia, May 24-26 2007.

7. Sibarani, J., Khairi, S., Yoeswono, Wijaya, K., dan Tahir, I., 2007, Pengaruh Abu Tandan Kosong Sawit pada Transesterifikasi Minyak Sawit menjadi Biodiesel, Indo. J.Chem., 7 (3), 314-319.

8. Knothe, G., 2000, Monitoring a Progressing Transesterification Reaction by Fiber-Optic Near Infrared Spectroscopy with Correlation to ${ }_{1}^{1} \mathrm{H}$ Nuclear Magnetic Resonance Spectroscopy, JAOCS, 77, J 9483, 489-493.

9. Darnoko, D., dan Cheryan, M., 2000, Kinetics of Palm Oil Transesterification in A Batch Reactor, J. Am. Oil Chem. Soc., 77, 19574, 1263-1267.

10. Kurata, S., Yamaguchi, K., dan Nagai, M., 2005, Rapid Discrimination of Fatty Acids Composition in Fats and Oils by Electrospray Ionization Mass Spectrometry, Jpn. Soc. Anal. Chem., 21, 1457-1465.

11. Knothe, 2005, Dependence of Biodiesel Fuel Properties on the Structure of Fatty Acid Alkyl Esters, Fuel Proc. Tech., 86, 1059-1070.

12. Kac, A., 2000, The Two-Stage Adaptation of Mike Pelly's Biodiesel Recipe (For Advanced Biofuelers), http://journeytoforever.org/, 6 Maret 2008.

12. Ma, F., dan Hanna, M. A., 1999, Biodiesel Production: a Review, Bioresour. Technol., 70, 1-15. 